\title{
Outsourcing in the Italian NHS: a Measure of Mismatch between Private and Public Operators*
}

\author{
Paolo Mariani ${ }^{* *}$, Rosa Falotico ${ }^{* * *}$, \\ Biancamaria Zavanella ${ }^{* * * *}$, Mauro Mussini ${ }^{* * * * *}$
}

\begin{abstract}
Outsourcing is a useful tool for improving partnership between private and public companies. The budgetary constraints recently imposed by the Italian government on health industry are enhancing the urgency to outsource in order to cope the cost containment.

Our study deals with the relationship between ASLs (Aziende Sanitarie Locali, the Italian local health authorities) and private operators outsourcing in Italy. In particular we hypothesize that the level of matching between public demand and private supply of outsourcing can affect the outsourcing development in Italian National Health Service. Under this hypothesis we present an analysis that aims at quantifying the level of mismatch between pharmaceutical companies offer and ASL needs in order to understand the future developments of outsourcing.

We studied 44 pharmaceutical companies (with a yearly turnover of about $€ 6$ billion) and 34 ASLs (with about 12 million users) to find out the areas in which they used outsourcing, their satisfaction and their future intentions. We analysed the answers in order to measure the level of convergence between public and private interests in outsourcing.

To quantify the convergence for each area we used a mismatch index to measure the discrepancy between public and private operators outsourcing activities. The results suggest that public and private outsourcing have a low mismatch which seems increasing in the future.
\end{abstract}

Keywords: Outsourcing; Italian Pharmaceutical Industry; Mismatch Index; Healthcare Operators Satisfaction

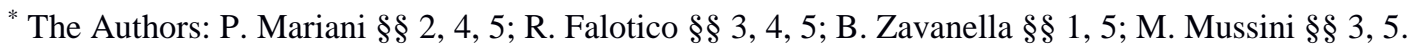

** Full Professor of Economic Statistics, University of Milan-Bicocca (paolo.mariani@unimib.it)

*** Research Assistant in Economic Statistics, University of Milan-Bicocca (rosa.falotico@unimib.it)

**** Full Professor of Economic Statistics, University of Milan-Bicocca (biancamaria.zavanella@unimib.it)

***** Assistant Professor of Economic Statistics, University of Verona (mauro.mussini@univr.it)
} Italian NHS: a Measure of Mismatch Between Private And Public Operators, Symphonya. Emerging Issues in Management (symphonya.unimib.it), n. 1, pp. $66-80$. 


\section{Introduction}

The stunning growth of the technological progress and the economic crises tend to increase uncertainty. Companies are forced to limit the economic exposure and to defend their market shares. To face these problems, private companies developed a wide range of business management tools and, nowadays, even public companies are starting to apply them.

In this study we focused our attention on outsourcing, a way to increase flexibility in Public Healthcare services, and in particular on its development in Italian Public Healthcare companies. Italy is one of the worst hit countries by the sovereign debt crisis. The Italian Public Health sector, although not subject to the competitive market rules, is facing severe budget restrictions, depending on the Central Government need of spending reduction (Fattore 2012).

Italian policy makers need to limit national debt and preserve high quality standards in the crucial area of Public Healthcare intervention, so an improvement of efficiency in the health services delivery is proposed. Moreover, the Central Government has undertaken a process of devolution (not yet completed), that has given greater autonomy to local authorities. National policy makers aim at increasing flexibility and efficiency in public healthcare services and making local governments more responsible about their healthcare spending.

These new operational conditions allow the Public Healthcare sector to outsource more extensively. Outsourcing is a business tool largely employed in the private sector in order to increase flexibility and to contain costs. Its use in the public sector is increasing and various studies analysed its development (Macinati 2008a).

We hypothesize that the level of matching between public demand and private supply of outsourcing can affect the outsourcing development in Italian National Health Service. Under this hypothesis we present an analysis that aims at quantifying the level of mismatch between pharmaceutical companies offer and ASL needs in order to understand if there are opportunities for further expansion of outsourcing.

Partnership between public and private operator are very important because public operators benefit from the managerial skill to improve efficiency, and business companies can associate their brand to ethical and social values (Risso 2012). Furthermore, partnership is a critical success factor of outsourcing (Lee, Kim 1999).We aimed at identifying the current state and future prospects of partnership between public and private operators: we employed a statistical measure of mismatch to assess the degree of correspondence between the specific services offered by pharmaceutical companies and the same services required by the ASLs.

By means of the mismatch index, in our work we provide a summary of the phenomenon of collaboration between health authorities and pharmaceutical operators as a whole, but also broken down into its individual components.

For our purposes, we use the results of a survey carried out in Italy on particular activities outsourced by territorial health agencies: the ASLs (Aziende Sanitarie Locali, the Italian local health authority). We analysed specific outsourced healthcare services (complementary services), not related to ASLs core activities (services of medical care and diagnosis) but characteristic enough for the public health care. The complementary services analysed in this paper are: clinical trials, epidemiological / observational studies, patient focused projects, management 
training, data release/ ad hoc research, patient monitoring, social marketing, CME (Continuing Medical Education).

These services are taken in charge by pharmaceutical companies, qualified interlocutors having the appropriate level of expertise to carry out such activities. Therefore, we interviewed outsourcing policy makers, within the ASLs, and managers handling the relations with the Public Healthcare within the pharmaceutical companies.

In order to produce an exhaustive description of outsourcing in Italian Healthcare System, in this survey we also collected information on satisfaction of outsourcing by both the involved actors.

This study is structured as follows. Section 2 shows the framework in Italian Healthcare Public sector, Section 3 describes the research strategy and data collection. In section 4, we present the empirical analysis and the results. Section 5 concludes.

\section{Theoretical Framework}

Italy is a country of 60 million of inhabitants (ISTAT 2013), ranked between the world's twenty-fourth most-developed country in 2010 for GDP (Gross domestic product) and for quality of life (Simone et al. 2013). The current global crisis and the huge changes (geopolitical, geoeconomic, demographic, technological, climatic) taking place worldwide, are forcing all countries, and in particular Italy, to reorganize public policy, focusing on cost containment and efficiency increase.

Italy, because of its high public debt, is one of the countries most severely affected by the financial crisis of recent years, and Public Healthcare is a sector more exposed to organizational restructuring. The Italian National Health Service (NHS), in addition to the problems of an aging population and an increasing migration, also faces the recent deterioration of the country's economy (Fattore 2012).

Until the late Seventies, healthcare in Italy was managed by a broad network of publicly funded private organizations and institutions, not necessarily well integrated with each other. This system was generally inefficient and a large part of the population lacked health coverage. For this reason, in 1978 the Italian National Health Service was created, driven by principles of universality, solidarity, territorial and inter-class comprehensiveness (Simone et al. 2013).

The effort to maintain a high level of service quality required a massive outflow of resources, that mainly weighed on the national budget, principally because the policies were sometimes not subject to economic evaluation on their effectiveness and efficiency. The result was a state of long term macroeconomic unsustainability, which today is no longer acceptable, given the severe economic crisis affecting Italy.

At this juncture, decisive measures are required. In recent years, the political debate on the reorganization and rationalization of public spending in healthcare has been very intense. In the field of healthcare budgets management, literature and policy makers followed two main themes (Macinati 2008a): 1) Devolution and 2) Improvement of public services management efficiency.

1. Devolution consists in the transfer or delegation of power to a lower level, especially by Central Government to local or regional administration. The 
devolution of powers and responsibilities at a sub-national level began several years ago, starting from the reform of 'Title V' of the Italian Constitution in 2001. By this amendment, the Italian regional institutions have become directly responsible for the organization and financial management of health policies.

The National Government maintained an active coordination on public health systems and, in order to ensure uniformity in the minimum level of health care to be provided to residents, in 2001 enacted the LEA (Essential Levels of Care) decree (Macinati 2008a; Cappellaro et al. 2009; de Belvis, et al., 2012). Devolution is a response to the demand for greater local autonomy, but it can also be seen as a requirement for an efficiency improvement in services management. In fact, thanks to these reforms, the local health decision makers assumed greater financial responsibilities, but at the same time, gained more decision-making power. This has allowed them to employ more effective operational management tools.

2. The demand for greater efficiency in the delivery of public services is a result of heavy public debt crisis of 2011, when the Italian government needed to restructure the whole sector of Public Spending, including the predominant component of health care area. Firstly, the response of the central government was dictated by the urgency and the gravity of the situation. The counter measures resulted mostly in 'linear cuts' in public spending and in health spending in particular. Leaving aside considerations about the effectiveness of such policies, some authors highlighted the potential increase in inequality in access to health care and an amplified gap between the Italian regions due to the drastic and sudden reduction in public health expenditure (Cappellaro et al. 2009).

As an alternative to indiscriminate cuts in public spending, literature long proposed several business instruments to enhance flexibility and efficiency. In particular, regarding the best use of available public administration resources, it is possible to refer to a train of thought that has been developed in literature for several years: strategic management (Fattore 1999).

In the context of a wider decision-making autonomy of public providers, strategic management aims at identifying the incentives for adoption of innovative and flexible business tools, so far neglected by policy makers. The indication of strategic management had not immediately been transposed into Italian law, and for several years they remained at the level of orientation.

Nowadays, finally, the local decision makers are giving a more managerial orientation to their policies, aware of the evident benefits it brings in terms of efficiency increasing in public activity (Macinati 2008b). Outsourcing is one of the tools that best fit these needs.

Outsourcing consists in transferring services or operating functions, traditionally performed internally, to a third party service provider and controlling the sourcing through contract and partnership management (Roberts 2001). It can be viewed in terms of strategic management and lean organization and its utility can be assessed according to the considered process, which can be closer to the core business activities or to the operational areas.

Literature lists various motivations and benefits of outsourcing. There are three major motivations for outsourcing: public spending cuts, public health development strategies, health policy targets. The first two benefit commonly drive outsourcing 
in private industry. Political agendas often drive outsourcing in public organizations (Kremic et al. 2006), but also public operators are interested in cost saving and strategic opportunity.

In fact the main reasons for outsourcing in the public health care (Roberts 2001; Young 2002, 2005; Billi et al. 2004; Kremic et al. 2006) can be summarized in cost reductions and efficiency improvements; strategic considerations (core activities should be enhanced so that the company remains on the market but ancillary activities have to be strategically outsourced in order to gain competitiveness); acquisition of specialized technical skills concentrating resources on the development of internal strategic skills.

Even though outsourcing may have many potential benefits, there are also several disadvantages (Roberts 2001): cost savings lower than expected and not available over the long term; public healthcare providers over-dependent on the vendor or liable for the vendor's actions; public healthcare losing control over the standard of service delivering.

A further problem concerns the matching between demand and supply of outsourcing. Collaboration between the parties takes place when the activities required by public companies correspond to those offered by the private sector. In our work we intend to provide an overview of the Italian situation in relation to this problem. We measure the gap between supply and demand for outsourcing in healthcare using the index of mismatch $\mathrm{I}^{\mathrm{M}}$, firstly proposed by Mariani and Zavanella ${ }^{1}$. Before introducing technical instruments, we provide a presentation of the actors involved in outsourcing partnerships.

On the demand side, the main actors involved in Public Healthcare outsourcing activities are primarily the great Italian health companies, such as Hospitals and $\mathrm{ASLs}^{2}$. In this work we have chosen to consider only this latter and, in effect, ASLs differ from hospitals because they both deliver care, but ASLs also deliver services, which are the object of our study.

The Local Health Authority organizational structure, originally involves the direct dependence of management by regional political bodies: the 'Assessorato alla sanità' (regional Department responsible for healthcare). After the Amato reform of 1992, the corporatization of the ASL introduced the principles of economic management of resources. The operational outsourcing management directly involves the hospital activities, the territorial activities, pharmaceutical services, as well as the ASL treasurer, the operating units of training and the remaining operational agencies.

In the public sector, specifically in the healthcare area, outsourcing consists overall in contracting-out: the public decision maker commits the services production/supply to private external companies. The range of services that NHS and in particular ASLs already contract-out is very wide, but the outsourced activities may be included in 4 main categories (Macinati 2008a): essential services (e.g. medical care, nursing, etc.), diagnostic services (e.g. Magnetic resonance imaging, ultrasound, X-rays), community services (e.g. integrated home care), ancillary services (general, admission and maintenance services). The last two categories can be grouped on the category 'complementary services' because both are not necessary for the development of core business interest of ASL.

Actually, the major advantages of outsourcing are that ASLs can concentrate economic resources and know-how on core business activities (in the case of Public Healthcare, they primarily consist of medical and diagnostic services), so they can 
commit to specialized external the complementary activities (ancillary clinical activities and community services). For this reason the services analysed are fully included in the definition of complementary activities (clinical trials, patient focused project, social marketing, CME etc.).

Given the specific technical skills required for the provision of such activities, the key partners for collaboration are pharmaceutical companies operating in Italy.

We have now defined the main subjects of this research, in the following section we present the methodology used in the analysis and the statistical tool we used to measure the mismatch between demand and offer of complementary services.

\section{Methods and Data Collection}

For our purpose, a survey was carried out to collect data on activities outsourced by ASLs and supplied by pharmaceutical companies. The questions affected the current state of outsourcing and the future prospects.

\section{The mismatch index}

In order to quantify the matching degree between demand and supply of outsourcing we used the mismatch index $\mathrm{I}^{\mathrm{M}}$, based on the comparison between the number of services offered by private operators for each activity and the number of requests by ASLs for those activities. $\mathrm{I}^{\mathrm{M}}$ varies in the $[0,1]$ interval. It is equal 0 when occurs perfect correspondence between supply and demand for each activity; the index is equal 1 when a situation of maximum imbalance occurs.

\section{The satisfaction degree deriving from outsourcing}

In order to give a broader framework, we inserted in the questionnaire a question specifically dedicated to the outsourcing satisfaction. There are many examples of analyses of satisfaction in healthcare, but they mainly regard customer satisfaction (Knox et al. 2003). In this research, we aimed at analysing and compare satisfaction of both the operators involved in outsourcing (ASL and private operators).

This work offers a representation of the current state of outsourcing in the Italian Healthcare System and a first indication of possible contrasts in the relationship between public and private partners. The research hypothesis was set up using a five-point Likert-type scale (from 'very unsatisfied' to 'very satisfied'). This analysis is purely exploratory: The amount of data available is not large enough and we cannot apply the most advanced satisfaction analysis tools (Parasuraman et al. 1994; Fornell et al. 2005).

\section{The questionnaire}

The data was collected in 2010. A different questionnaire was administered to ASLs and pharmaceutical companies. The CATI method was used.

The questionnaire was structured with closed-ended question about the level of satisfaction derived from the collaboration. Moreover, complementary services mentioned in section 2 were recorded. In the questionnaire the following 8 types of relevant activities were identified: patient focused projects, clinical trials, epidemiological/observational studies, managerial training, data release/ ad hoc research, patient monitoring (compliance to treatment), social marketing, CME (Continual Medical Education). We chose these activities because ASLs have the responsibility to provide them, but they do not represent a core business service for 
Public Healthcare: this is a classic example of services economically convenient to outsource.

The issues regarding outsourcing activities, already in place and future, have been presented differently to respondents. ASLs were asked what activities they have and have intention to outsource. Pharmaceutical companies were asked to indicate what might be, for the Public Healthcare policy maker, the most interesting activities to be placed in outsourcing (among those already in place and among those which have yet to be put in place). In fact, we assume that the answers to this question are influenced by the relationships between respondents and Public Healthcare.

\section{The respondents}

On the demand side, all 146 ASLs operating in Italy in 2010 were contacted (source: Ministry of Health 2013). 34 ASLs responded to survey, covering about 12 million of users (nearly one-fifth of the Italian population).

On the supply side, 44 pharmaceutical companies participated in the survey. They summarize approximately $€ 6$ billion annual turnover in Italy and cover about $30 \%$ of the pharmaceutical product sales in Italy, slightly less than $€ 20$ billion (source IMS Health 2010).

As the data obtained includes a self-selected subset of the population, it is not possible to draw inferential conclusions from the analysis. On the other hand, the survey enables to outline an overview of the state of outsourcing in the Italian Public Healthcare System.

\section{Results}

First of all, the research findings pointed out the differences between the satisfaction level of public and private operators. The median satisfaction for public companies is equal to 4 ('satisfied'), compared to a value of 3 ('moderately satisfied') for private companies. In fact, most of the Pharmaceutical companies are moderately satisfied (52.4\%), slightly more than $40 \%$ of the respondents are 'satisfied' or 'very satisfied'. About $7 \%$ of respondents said they were 'very unsatisfied'. On the contrary, no ASL respondent is dissatisfied. More than half of the public operators are satisfied, and $12.9 \%$ of respondents said they were very satisfied. About a third of public companies said they were slightly satisfied for outsourcing.

The typology of outsourced activities and the analysis of imbalance in healthcare outsourcing

Assuming that respondent ASLs represent all the Local Health care organizations, in Figure 1 we summarize the information about the type of outsourced activities in collaboration with the whole Italian pharmaceutical industry. The activities of 'clinical trials', 'CME' and 'epidemiological / observational studies' are the most outsourced by ASL. The 'social marketing' activities, in general, are not of primary importance. The expected general decline in outsourcing for the next period is reflected in each activity in a not perfectly homogeneous way that causes a redistribution of the percentages per activities. 'Management training' is expected to have the less decrease and to become, in the future, the more required activity. 
On the contrary, 'release date / ad hoc research' is the activity with the largest drop: it is expected to become the less demanded activity.

In the case of pharmaceutical companies, assuming respondent companies representative of Italian pharmaceutical market, and analysing data reported in Figure 2, we observe that the decline in outsourcing to the private sector is smaller and almost generalized.

Figure 1: Percentage of ASLs Outsourcing Complementary Activities per Period

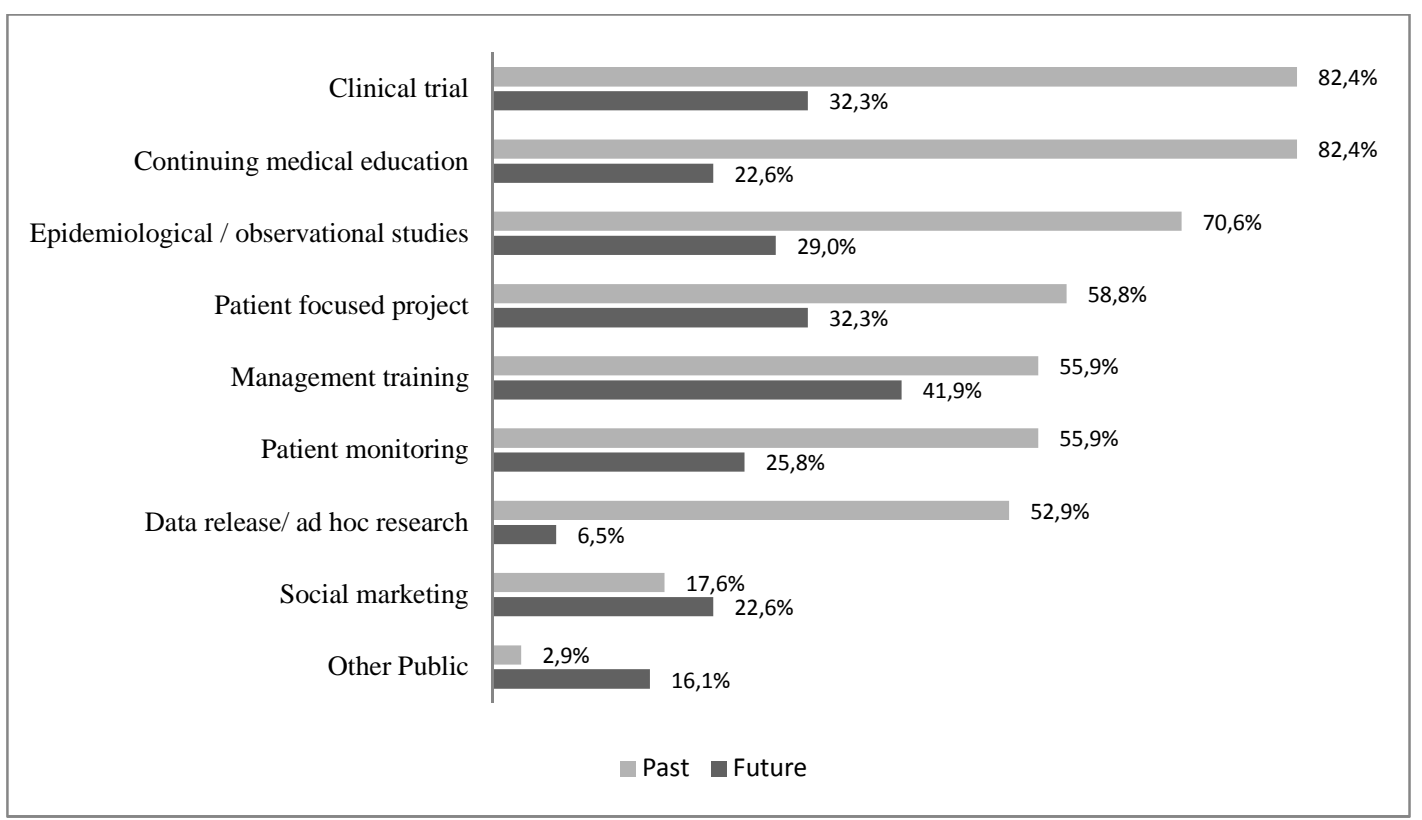

Source: Research Centre B-ASC. Based on research data.

Figure 2: Percentage of Pharmaceutical Companies Collaborating in Outsourcing Complementary Activities per Period

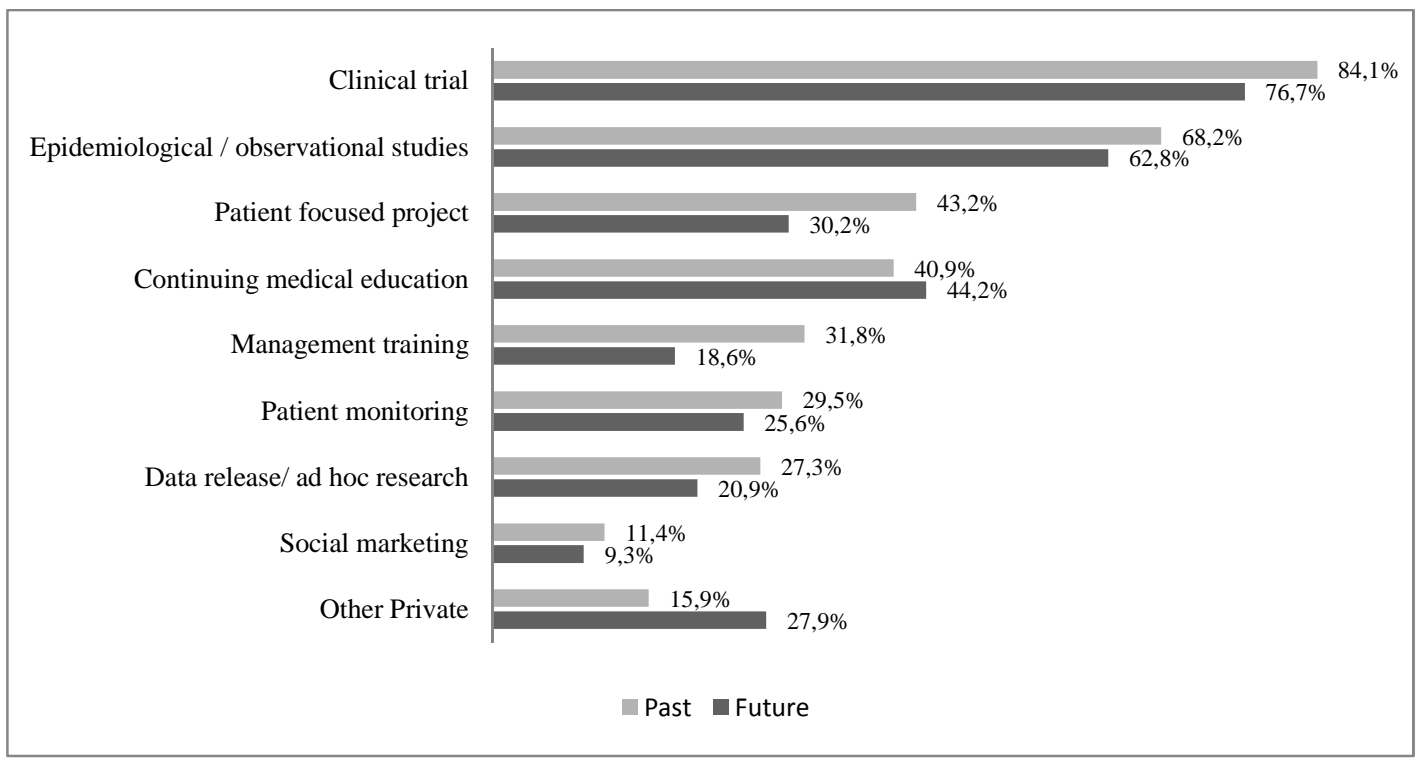

Source: Research Centre B-ASC. Based on research data. 
This substantial difference in the expected change in use of outsourcing affects the imbalance between supply and demand. We note that not all the respondent ASLs collaborated with the respondent pharmaceutical companies and vice versa. We can make a comparison between public and private outsourced activities by assuming that both respondents are representative of the respective population. In this case, comparing the outsourcing of the two subjects per period, we note that, as regards the past, there is a not strong discrepancy, although there is a not perfect matching between the ASLs needs and the perception of private companies. To quantify the level of existing mismatch, we use the index $\mathrm{I}^{\mathrm{M}}$, introduced in previous section. This index takes into account the overall number of demanded and offered activities, providing an overall assessment. The value obtained from the collected data is equal to 0.164 . Since the index ranges between 0 and 1 , we can say that the imbalance is low: there is a substantial agreement among the respondents. Using the decomposition properties of $\mathrm{I}^{\mathrm{M}}$, we can detect the activities which mainly contribute to mismatch. In the analysis the public sector activities without exact corresponding activities in private sector were aggregated in a single category named 'Other Public'. Vice versa 'Other Private' includes activities indicated by the pharmaceutical companies but not mentioned by respondent ASLs. In this way, the overall contribution can be gauged, without getting into the specific characteristics of each single 'other' activity. Obviously, the contribution to the total value of the mismatch depends on the number of activities, but the value of the partial mismatch for both 'Other' categories is maximum (equal to 1 in absolute value). Table 1 (column 1) shows that the imbalances tend to be one-sided; in the examined data, the amount of the pharmaceutical supply exceeds the ASLs' demand only for activities related to clinical trials and epidemiological / observational studies (excluding the obvious case of services classified as 'Other Private').

Table 1: Mismatch Value per Outsourced activities-Past

\begin{tabular}{|c|c|c|c|c|}
\hline Outsourced activities-Past & $\begin{array}{l}\text { Unbalance } \\
\text { direction }\end{array}$ & $\begin{array}{l}\text { Mismatch } \\
\text { orientation } \\
\text { per activity }\end{array}$ & $\begin{array}{l}\text { Mismatch } \\
\text { strength per } \\
\text { activity }\end{array}$ & $\begin{array}{l}\text { Contribution } \\
\text { per activity }\end{array}$ \\
\hline & Column 1 & Column 2 & Column 3 & Column 4 \\
\hline Clinical trials & Pub $<$ Priv & 0.138 & 0.138 & 0.028 \\
\hline $\begin{array}{r}\text { Epidemiological/observation } \\
\text { al studies }\end{array}$ & Pub $<$ Priv & 0.111 & 0.111 & 0.019 \\
\hline Patient focused projects & Pub>Priv & -0.026 & 0.026 & 0.003 \\
\hline Management Training & Pub>Priv & -0.152 & 0.152 & 0.016 \\
\hline $\begin{array}{r}\text { Data release/ ad hoc } \\
\text { research }\end{array}$ & Pub $>$ Priv & -0.200 & 0.200 & 0.019 \\
\hline Patient Monitoring & Pub>Priv & -0.188 & 0.188 & 0.019 \\
\hline Social marketing & Pub>Priv & -0.091 & 0.091 & 0.003 \\
\hline $\begin{array}{r}\text { Continuing medical } \\
\text { education }\end{array}$ & Pub $>$ Priv & -0.217 & 0.217 & 0.031 \\
\hline Other Public & Pub>Priv & -1.000 & 1.000 & 0.003 \\
\hline Other Private & Pub<Priv & 1.000 & 1.000 & 0.022 \\
\hline Total mismatch (Past) & & & & 0.164 \\
\hline
\end{tabular}

Source: Research Centre B-ASC. Based on research data. 
Using the partial form of $\mathrm{I}^{\mathrm{M}}$ index, we measure mismatch for each distinct activity (Table 1, column 3): clinical trials, taken separately, are one of the activities affected the least by imbalance (the level of partial mismatch is equal to 0.138 , which is only higher than the mismatch calculated for epidemiological / observational studies, for patient focused projects and for social marketing). On the contrary, if we exclude the activities indicated with 'Other', by construction maximally unbalanced, 'CME' is still the service with greatest dystonia (level of partial mismatch equal to 0.217 ), followed by 'data release/ ad hoc research' (level of partial mismatch equal to 0.200). We can detect the specific contributions of each activity to the total level of mismatch. Table 1, column 4 shows that clinical trials and the CME have a major role in determining mismatch with contributions equal to 0.028 and 0.031 , respectively. This occurs because the index $\mathrm{I}^{\mathrm{M}}$, even in its partial version, weighs the difference between supply and demand for the overall frequency of each activity. So the mismatch intensity for clinical trials, reaching 65 activities between demand and supply, weighs much more than 'data release/ ad hoc research', which only sums 30 activities. The least important activities are the patient focused projects (with a contribution equal to 0.026) and social marketing (with a contribution of 0.091). The contribution of the 'Other' activities is very interesting. The contribution of 'Other private' shows how there are many services that are overvalued by pharmaceutical companies and not of interest to ASLs, while the low value of 'Other Public' (0.003) indicates that the core activities for ASLs are correctly identified by the private operators. The research findings have shown, a low level of mismatch between the perception of the private companies and the ASLs real needs. On the other hand, private companies tend to manifestly underestimate the interest of public companies towards outsourcing in some sectors. The following research question is: will the slowdown of ASLs investment in outsourcing tend to change the mismatch level in the future?

Table 2: Mismatch Value per Prospected Outsourcing Activities. Future

\begin{tabular}{|r|c|c|c|c|}
\hline $\begin{array}{c}\text { Prospected outsourcing } \\
\text { activities- Future }\end{array}$ & $\begin{array}{c}\text { Unbalance } \\
\text { direction }\end{array}$ & $\begin{array}{c}\text { Mismatch } \\
\text { orientation } \\
\text { per activity }\end{array}$ & $\begin{array}{c}\text { Mismatch } \\
\text { strength per } \\
\text { activity }\end{array}$ & $\begin{array}{c}\text { Contribution } \\
\text { per activity }\end{array}$ \\
\hline Clinical trials & Pub<Priv & 0.535 & 0.535 & 0.111 \\
\hline Column 1 & Column 2 & 0.500 & 0.087 \\
\hline studies & Pub<Priv & 0.500 & 0.130 & 0.014 \\
\hline Patient focused projects & Pub<Priv & 0.130 & 0.238 & 0.024 \\
\hline Management Training & Pub>Priv & -0.238 & 0.636 & 0.034 \\
\hline Data release/ ad hoc research & Pub<Priv & 0.636 & 0.158 & 0.014 \\
\hline Patient Monitoring & Pub<Priv & 0.158 & 0.273 & 0.014 \\
\hline Social marketing & Pub>Priv & -0.273 & 0.462 & 0.058 \\
\hline CME & Pub<Priv & 0.462 & 1 & 0.024 \\
\hline Other Public & Pub>Priv & -1 & 1 & 0.058 \\
\hline Total mismatch (Future) & & 1 & & $\mathbf{0 . 4 4 0}$ \\
\hline
\end{tabular}

Source: Research Centre B-ASC. Based on research data. 
The strong decrease occurred between the two periods, influences the balance between future supply. Actually the index value for the future is equal to 0.440, which is considerably greater than 0.164 (calculated for the past activity). The general decrease in demand for outsourcing activities by ASLs is not fully perceived by the private.

Through a further investigation of the determinants in the new level of mismatch, we can see (Table 2) that the increase in the index is not due to the accentuation of a particular situation, but to a general increase in the intensity of the mismatch for single activities (excluding the case of monitoring patients for which this value decreases from 0.188 to 0.158 ).

It is worth mentioning that the mismatch does not increase in the same way for all activities. While the value of partial mismatch increase from 0.217 to 0.462 for CME, for epidemiological / observational studies, the same indicator increase from 0.111 to 0.500 . For patient focused projects we get a better match: the level only goes from 0.016 to 0.130 .

The changes in the supply and demand level also affect the composition of $\mathrm{I}^{\mathrm{M}}$. Clinical trials become the largest contributor (the value of the partial index for this activity increased from 0.028 to 0.111 ), while the CME contribution only decreases from 0.058 to 0.031 . The patient focused projects, patient monitoring and social marketing provide the smallest contribution to the change in the mismatch: for all three it is equal to 0.014 .

Figure 3: 2-Period Distribution of Outsourcing Activities

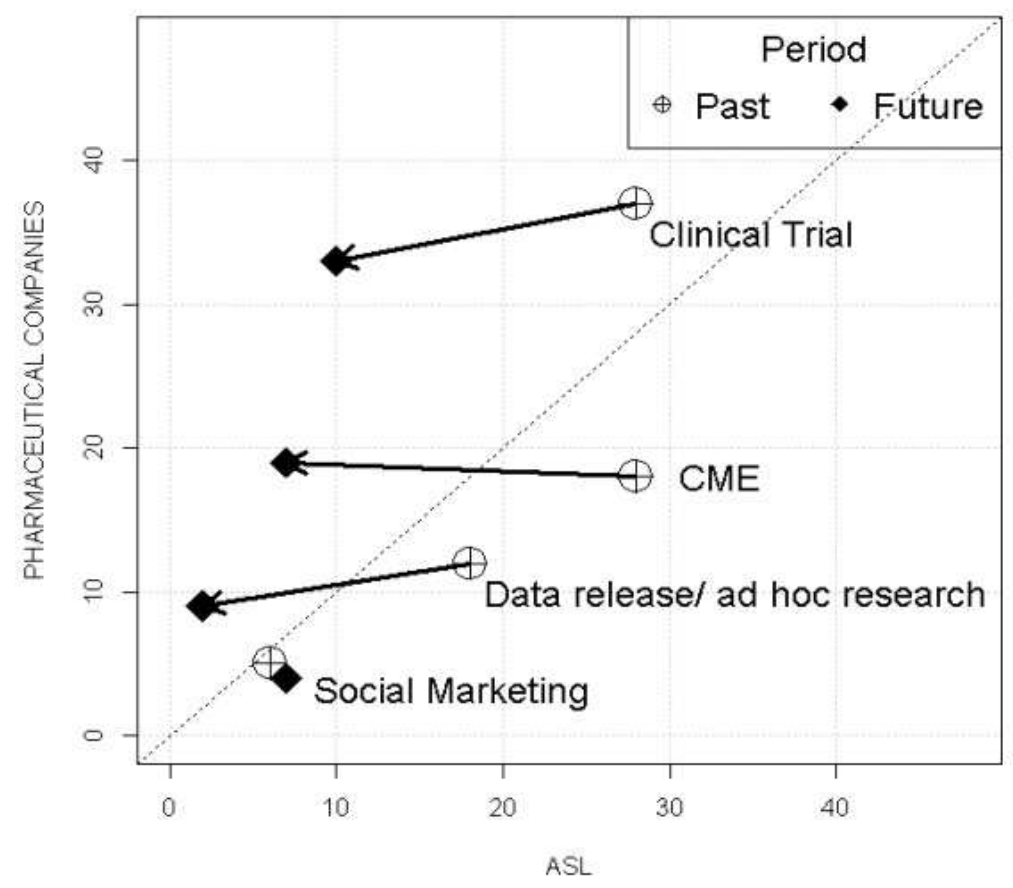

Source: Research Centre B-ASC. Based on research data. 
It is also interesting to evaluate the change in mismatch orientation for single outsourced services. In case of patient focused projects, data release/ ad hoc research, patient monitoring and CME, we move from a surplus of public demand to an excess of private offer.

These results are in contrast with the level of satisfaction declared by operators. Although ASLs are generally more satisfied than pharmaceutical companies, they expect a considerable reduction of outsourced activity. This is evident from the graph in Figure 3, where only a few variables with interesting changes are represented.

In the graph, on the $\mathrm{x}$-axis and on the $\mathrm{y}$-axis, the number of activities carried out by ASLs and the number of activities considered relevant by pharmaceutical companies are plotted. The bisector of the first quadrant represents perfect equilibrium: all services required, corresponding to as many services provided, so the distance from the bisector is a further indicator of mismatch.

In the plot, crossed circles and diamonds represent the level of past and future activities: the shift occurred for each activity provides useful information on the phenomenon.

The 'social marketing' is the activity with the smallest deviation: in fact it is also one of the least outsourced activities. Regarding clinical trials, the shift is considerable, but the mismatch direction does not change (in both time periods private offer is predominant with respect to public demand). The extensive decrease in the expected number of outsourcing activities by public operators increases the divergence. 'CME' and 'data release/ ad hoc research' show a marked change in amount and in direction.

The variation in the number of activities is not reflected too much on the mismatch (the two points past and future, remain quite close to the bisector), but it definitely affects the direction of the relationship. In fact crossing the bisector from the lower to the upper half quadrant, implies that, in the first period, there is prevalence of public demand while in the second period private offering prevails. It is clear that ASLs are determinant in the variation in mismatch level. The $\mathrm{x}$-axis component of the shift (indicating the general decrease in demand) is predominant with respect to the y-axis component (indicating the change in the pharmaceutical companies supply).

At present, the Public Healthcare outsourcing market shows that private provision and public demand essentially convergence, but in the future we expect an increase of mismatch, due in the first instance, to generalized loss of participation of public operators. The current state of outsourcing in Public Healthcare, emerging from this research, reveals a condition of misalignment between ASLs and pharmaceutical companies, because of the underestimation of the public needs by the private companies.

A Greater interaction on both sides is required, in particular on the theme of outsourcing, but in general, on the whole management of the relationship 'pharmaceutical companies - Public Healthcare'. This requirement has stimulated, in Italy, the employment of a market access manager professional. Among his broad expertise, the position of market access manager also includes the management of the activities performed in collaboration with the public operators. This professional allows to ASLs and pharmaceutical companies to exchange information in real time, helping to reduce the level of mismatch in this market. So, on the supply side, the introduction of managerial innovations facilitates the 
outsourcing phenomenon, but on the side of public health, the carrying out of outsourcing falls: although the local health authorities are generally satisfied with the result of the collaboration with the private sector, they plan to significantly reduce the use of outsourcing.

The information derived from this research provides a starting point for further investigation of the phenomenon. It would be interesting to check if the deterioration of the situation is due to the absence of interest in outsourcing as a tool for the recovery of flexibility and efficiency, to the financial squeeze or determined by the austerity policies of the Central Government.

\section{Conclusions}

Outsourcing is increasingly popular in the context of efficiency optimization for the Public Healthcare sector. This article has shown an overview of the outsourcing state in some specific areas of the Italian National Health Service in order to identify future prospects for cooperation between the public and private sectors. We have used a measure of mismatch $\left(\mathrm{I}^{\mathrm{M}}\right)$, to assess the correspondence between the services offered by pharmaceutical companies and those required by the ASLs.

Our results suggest that the outsourcing investments for the two categories of respondents vary in an opposite way if we consider the economic prospects. The pharmaceutical companies expect an increase in the level of average investment in outsourcing, while the ASLs predictions indicate a drastic resizing. This variation also affects the level of matching between public demand and private supply. The value of the $\mathrm{I}^{\mathrm{M}}$ index for current partnership is quite low (indicating a good correspondence between public and private requirement), while in the case of the predictions for the future, the $\mathrm{I}^{\mathrm{M}}$ index value shows a drastic increase in the discrepancy between supply and demand, mainly due to the significant reduction of the activities required by the ASLs (in particular Clinical trials, CME and data release/ ad hoc research).

These fluctuations certainly depend on the need of cost reduction and of 'linear cuts' in public spending; but the strategic alliance between outsourcer and outsourcee, that allows to create a relationship of mutual and long-term trust, enables to determine the organizational structure transformation of the NHS and achieves greater efficiency. Outsourcing choice can allow the ASLs to develop the core business activities (health care and medical care) and to facilitate the creation of highly specialized and efficient spin-off companies, candidates to handle the responsibilities accessories that are not strictly related to the health service.

Public administration should not break the outsourcing relationship flows with private companies for short-term cost savings, at the expense of long-term efficiency. The pharmaceutical companies have already gone down this path by introducing the figure of the market access (MA) manager or Public Affairs Managers (PAM) inside their organization, in order to make the relationship with the Public Healthcare sector more structured. It could be strategic for the public health policy makers to create an equivalent professional to make the cost saving plan of public healthcare services really effective and efficient. Moreover, it would be useful for pharmaceutical companies and local health authority to further develop the skills of the MA manager. 


\section{Bibliography}

Billi John E., Pai Chih-Wen, Spahlinger David A. (2004) Strategic Outsourcing of Clinical Services: A Model for Volume-Stressed Academic Medical Centers, Health Care Management Review vol. 29, n. 4, pp. 291-297.

Cappellaro Giulia, Giovanni Fattore, Aleksandra Torbica (2009) Funding Health Technologies in Decentralized Systems: A Comparison Between Italy and Spain, Health Policy, vol. 92, n. 2, pp. 313-321. http://dx.doi.org/10.1016/j.healthpol.2009.05.004

de Belvis Antonio G., Ferrè Francesca, Specchia Maria L., Valerio Luca, Fattore Giovanni, Ricciardi Walter (2012) The Financial Crisis in Italy: Implications for the Healthcare Sector, Health Policy, vol. 106, n.1, pp.10-16.

http://dx.doi.org/10.1016/j.healthpol.2012.04.003

Fattore Giovanni (1999) Cost containment and reforms in the Italian National Health Service (ed.) Mossialos Elias, Le Grand Julian, Health Care And Cost Containment In The European Union. Aldershot: Ashgate; p.513-46.

Fattore Giovanni (2012, May) The Impact Of The Three Crises On Health In Italy: Evidence And Lack Of Adequate Information Systems (ed.) 46TH Scientific Meeting of the Italian Statistical Society.

Fornell Claes, Van Amburg David, Morgeson III Foster V., Anderson Eugene W., Bryant Barbara E., Johnson Michael D. (2005) The American Customer Satisfaction Index at Ten Years. Ann Arbor: Stephen M. Ross School of Business.

Italian National Institute of Statistics- ISTAT. (2013) http://www.istat.it/en/archive/94537.

Jackman Richard, Roper Stephen (1987) Structural Unemployment, Oxford Bulletin of Economics and Statistics, vol. 49, n. 1, pp. 9-36.

http://dx.doi.org/10.1111/j.1468-0084.1987.mp49001002.x

Knox Kris J., Blankmeyer Eric C., Stutzman J. R. (2003) Organizational Efficiency and Quality in Texas Nursing Facilities, Health Care Management Science, vol. 6, n. 3, pp.175-188. http://dx.doi.org/10.1023/A:1024440123881

Kremic, Tibor, Tukel Oya Icmeli, Rom Walter O. (2006) Outsourcing Decision Support: A Survey of Benefits, Risks, and Decision Factors, Supply Chain Management: An International Journal, vol. 11 , n. 6 , pp. 467-482.

http://dx.doi.org/10.1108/13598540610703864

Lee Jae-Nam, Kim Young G. (1999) Effect of Partnership Quality on Is Outsourcing Success: Conceptual Framework And Empirical Validation, Journal of Management Information Systems, vol. 15, n. 4, 29-61. http://dx.doi.org/10.1016/S0378-7206(00)00074-4

Macinati Manuela S. (2008a) Outsourcing in The Italian National Health Service: Findings From a National Survey, The International Journal of Health Planning and Management, vol. 23, n. 1, pp. 21-36.

http://dx.doi.org/10.1002/hpm.902

Macinati Manuela S. (2008b) The Relationship between Quality Management Systems and Organizational Performance in The Italian National Health Service, Health Policy, vol. 85, n. 2, pp. 228-241. http://dx.doi.org/10.1016/j.healthpol.2007.07.013

Ministry of Health (2010) http://www.salute.gov.it/

Parasuraman Ananthanarayanan, Zeithaml Valarie A., Berry Leonard L. (1994) Reassessment of Expectations as a Comparison Standard in Measuring Service Quality: Implications for Further Research, The Journal of Marketing, pp. 111-124. http://dx.doi.org/10.2307/1252255

Risso Mario (2012) Exploring Partnership for Social Innovation, Symphonya. Emerging Issues in Management (symphonya.unimib.it), n. 2, pp. 26-36. http://dx.doi.org/10.4468/2012.2.03risso, 26-36 
Roberts Velma (2000) Managing Strategic Outsourcing In The Healthcare Industry, Journal of Healthcare Management/American College of Healthcare Executives, vol. 46, n. 4, pp. 239-249.

Simone Benedetto, Mazzucco Walter, Gualano Maria Rosaria, Agodi Antonella, Coviello Domenico, Dagna Bricarelli Francesca, Dallapiccola Bruno, Di Maria Emilio, Federici Antonio, Genuardi Maurizio, Varesco Liliana, Ricciardi Walter, Boccia Stefania (2013) The Policy of Public Health Genomics in Italy, Health Policy, vol. 110, n. 2, pp. 214-219. http://dx.doi.org/10.1016/j.healthpol.2013.01.015

Young Suzanne (2002) Outsourcing and Downsizing: Processes of Workplace Change in Public Health, The Economic and Labour Relations Review, 13(2), 244-269. http://dx.doi.org/10.1177/103530460201300206

Young Suzanne (2005) Outsourcing in The Australian Health Sector: The Interplay of Economics And Politics, International Journal of Public Sector Management, vol. 18, n. 1, pp. 25-36. http://dx.doi.org/10.1108/09513550510576134

\section{Notes}

${ }^{1}$ The index was proposed in: Mariani P., Zavanella B. (2008) Un indice per la misura del mismatch tra domanda e offerta di lavoro per laureati applicato alle fonti Excelsior e Centri per l'impiego. FABBRIS L.(editor) Definire figure professionali tramite testimoni privilegiati, Cleup, Padua, p. 215-230.

${ }^{2}$ For the Italian law, the Local Health Authority (ASL) is a local government agency that since 1993, according to the prevailing case law, has lost the character of the organ of the Region, acquiring its own legal personality, with an entrepreneurial character. 